Крохичева Г. Е., Д. э. н., проф. кафедры «Экономическая безопасность, учет и право», ДГТУ, Ростов-на-Дону, Россия; galina-krokhicheva@yandex.ru;

Лысюк М.А., студент 4 курса кафедры «Экономическая безопасность, учет и право» ФГБОУ ВО ДГТУ», Ростов-на-Дону, Россия; mary16_97@mail.ru

\title{
СОГЛАСОВАНИЕ ЭКОНОМИЧЕСКИХ ИНТЕРЕСОВ В СИСТЕМЕ ОБЕСПЕЧЕНИЯ ЭКОНОМИЧЕСКОЙ БЕЗОПАСНОСТИ СТРАНЫ
}

Аннотация. В статье анализируются теоретические аспекты обеспечения экономической безопасности страны с точки зрения политической экономии. Подходы к гармонизации экономических интересов рассматриваются, в первую очередь, в рамках создания условий для реализации национальных интересов России, служащих основой для устойчивого социально-экономического развития страны как неотъемлемого элемента ее экономической безопасности.

Ключевые слова: экономическая безопасность, национально-государственные интересы, экономические интересы, стабильность, экономические угрозы, система национальной безопасности страны.

Krokhicheva G.E., doctor of Economic Sciences, professor "Economic security, account and right" DGTU, Rostov-on-Don, Russia;

galina-krokhicheva@yandex.ru

Lysuk M.A., the student of "Economic Security, Account and Right" DGTU, Rostovon-Don, Russia; mary16_97@mail.ru

\section{AGREEMENT OF ECONOMIC INTERESTS IN THE SYSTEM OF ENSURING THE ECONOMIC SECURITY OF THE COUNTRY}

Annotation. The article analyzes the theoretical aspects of ensuring the economic security of the country from the perspective of political economy. Approaches to harmonizing economic interests are considered, primarily within the framework of creating conditions for the realization of Russia's national-state interests, serving as 
the basis for the country's sustainable socio-economic development as an integral element of its economic security.

KEY WORDS: economic security, national state interests, economic interests, stability, economic threats, the system of national security of the country.

Главным компонентом в системе национальной безопасности страны, а также на международном уровне является экономическая безопасность, так как для обеспечения стабильного развития экономики необходимы гарантии экономической безопасности. Важным элементом государственной безопасности Российской Федерации выступает экономическая безопасность. Согласно Федеральному закону № 390-ФЗ от 28.12.2010 (ред. от 05.10.2015) «О безопасности», экономическая безопасность - это защита жизненно важных интересов личности, общества и государства от внешних и внутренних угроз в экономической сфере [1].

Экономическая безопасность является одним из основных условий существования, а так же устойчивого и динамичного развития любого суверенного и единого государства. Значительное количество российских и зарубежных ученых, которые изучают проблемы экономической безопасности, определяют понятие безопасность по-разному.

В толковом словаре С. И. Ожегова, безопасность характеризуется как состояние, при котором не угрожает опасность, то есть присутствует защита от безопасности. По мнению американского политолога А. Уолферса, безопасность предполагает отсутствие угроз приобретенным ценностям, безопасность - это качество какой-либо системы, которое определяет ее возможность и стабильность к самосохранению.

Один из вариантов, рассмотренных Т.Г. Карпенко, характеризует экономическую безопасность как положение экономической системы, при котором она способна активно и результативно развиваться, решать задачи 
социального характера, а так же позволяет государству разрабатывать и реализовывать независимую экономическую [4, с. 57].

Один из вариантов, рассмотренных В.M. Володиным, определяет экономическую безопасность как состояние экономики и институтов власти, при котором обеспечиваются защита национальных интересов, социально направленное развитие страны и оборонный потенциал [3, с.49].

По мнению Л.И Абалкина экономическая безопасность - это состояние экономической системы, которое развивается эффективно, и решает социальные проблемы и задачи.

На наш взгляд, экономическая безопасность - это широкое понятие, которое включает в себя огромное количество компонентов и распространяется на сферы хозяйствования разного рода субъектов всех уровней.

Объектом экономической безопасности государства является экономическая система государства. Субъектом экономической безопасности выступают органы законодательной, исполнительной и судебной власти. Система экономической безопасности содержит ряд направлений, важным условием которых является механизм обеспечения экономической безопасности страны, который основан на выявлении внутренних и внешних факторов. Внутренние факторы оказывают влияние не только на экономическую безопасность страны, но и на ее возможности и перспективы развития. К ним относятся [3, с. 48-52]:
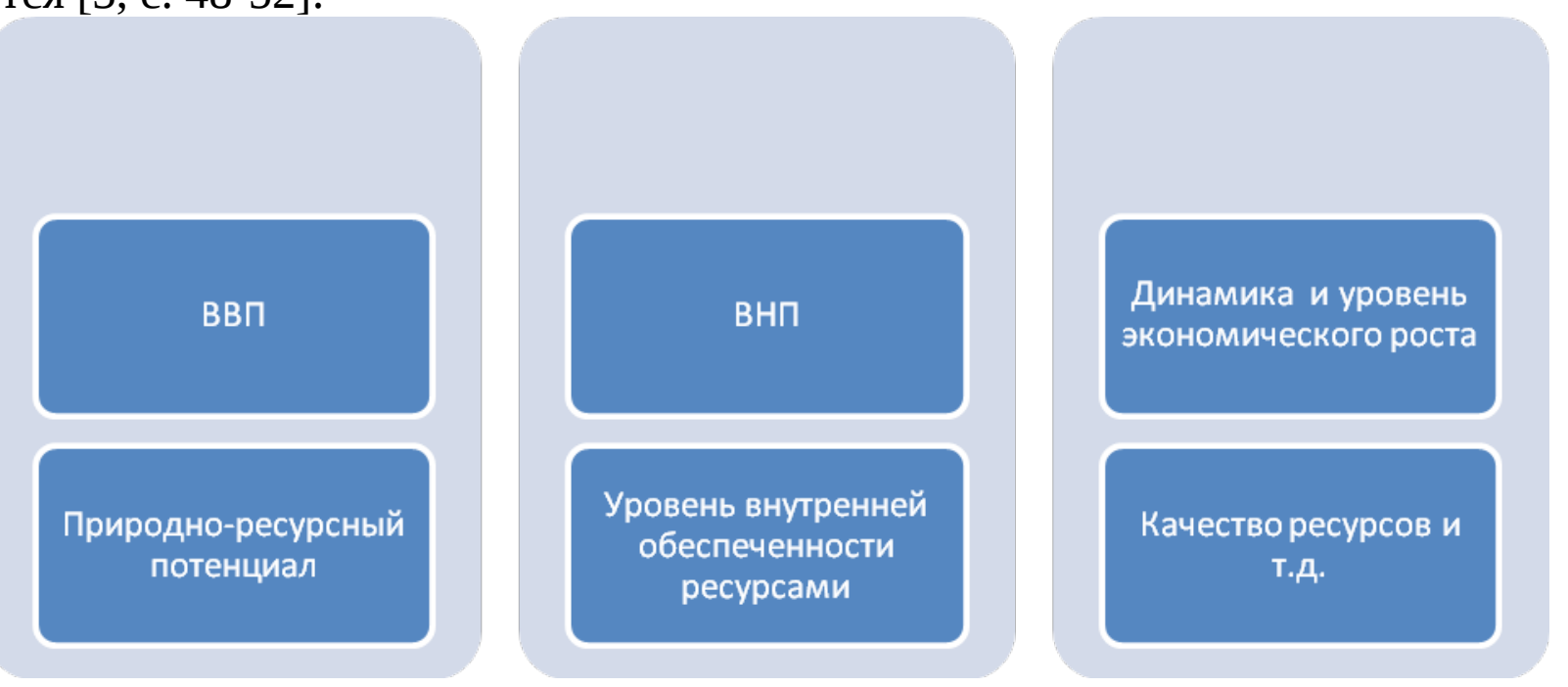

Рисунок 1. Внутренние факторы, оказывающие влияние на экономическую безопасность страны 
В настоящее время для обеспечения экономической безопасности России необходимы современные механизмы этой сферы. В современных условиях в механизме обеспечения экономической безопасности РФ выделяют такие элементы, как [5, с. 59]:

1) Мониторинг общества и экономики для прогноза внешних и внутренних угроз экономической безопасности.

2) Выработка предельных значений социально-экономических показателей, превышение порога этих показателей приводит к социальным конфликтам и нестабильности.

3) Показатели, характеризующие деятельность страны по выявлению и предостережению угроз экономической безопасности: различие национальных интересов; обострение экономической борьбы за пользование ресурсами, в связи с их ограниченностью; возрастание конкуренции в производстве и сбыте товаров и др.

K особенностям обеспечения экономической безопасности относятся [2, c. 99-102]:
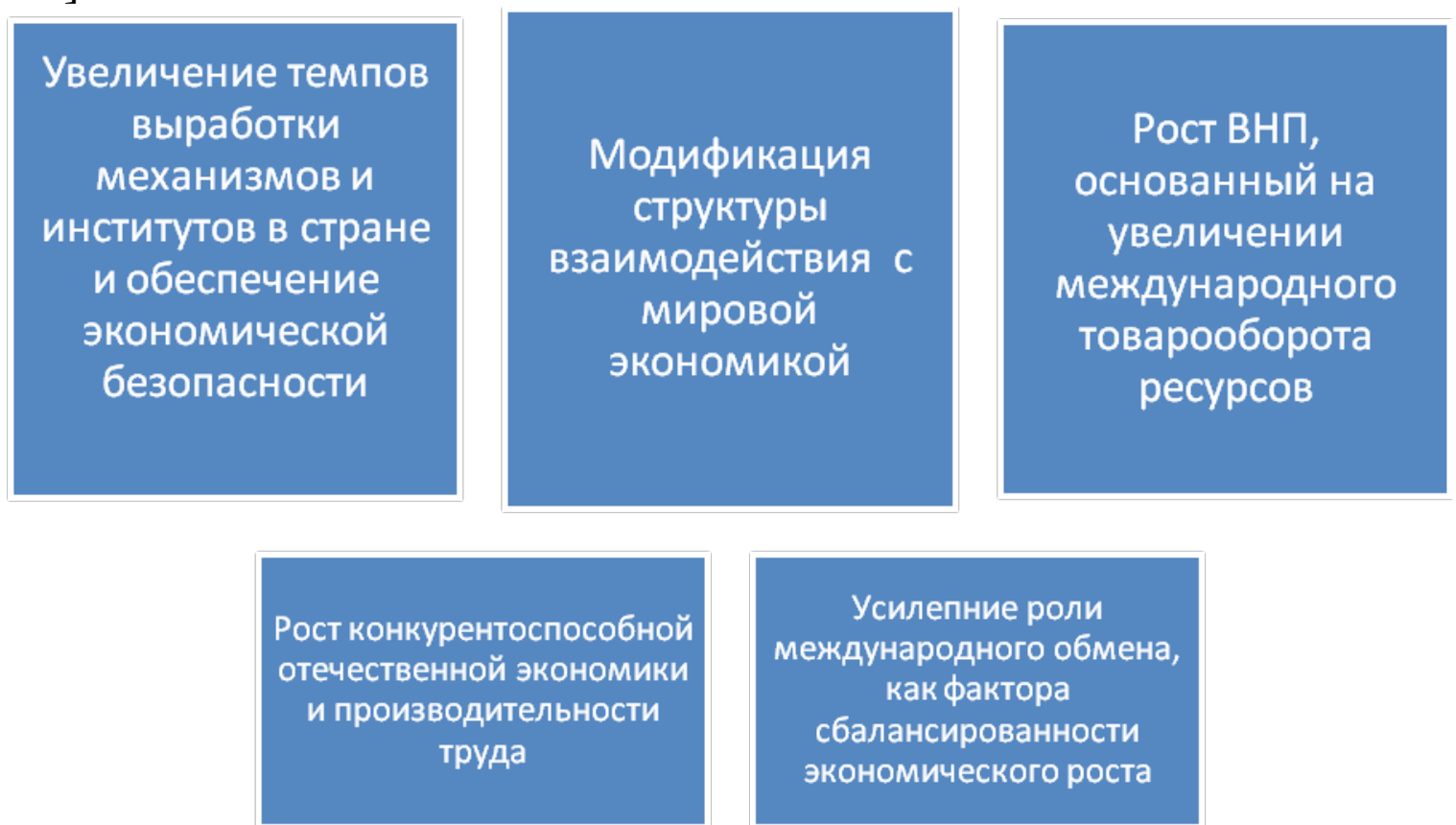

Рисунок 2. Особенности обеспечения экономической безопасности

В основе обеспечения экономической безопасности должна лежать возможность и готовность обеспечить микро- и макроэкономическую стабильность, в любых условиях и под влиянием любых факторов. 
Вышеперечисленные механизмы образуют систему управления экономической безопасности страны (рисунок 3).

\section{Государство-основной субъект управления экономической безопасностью страны}

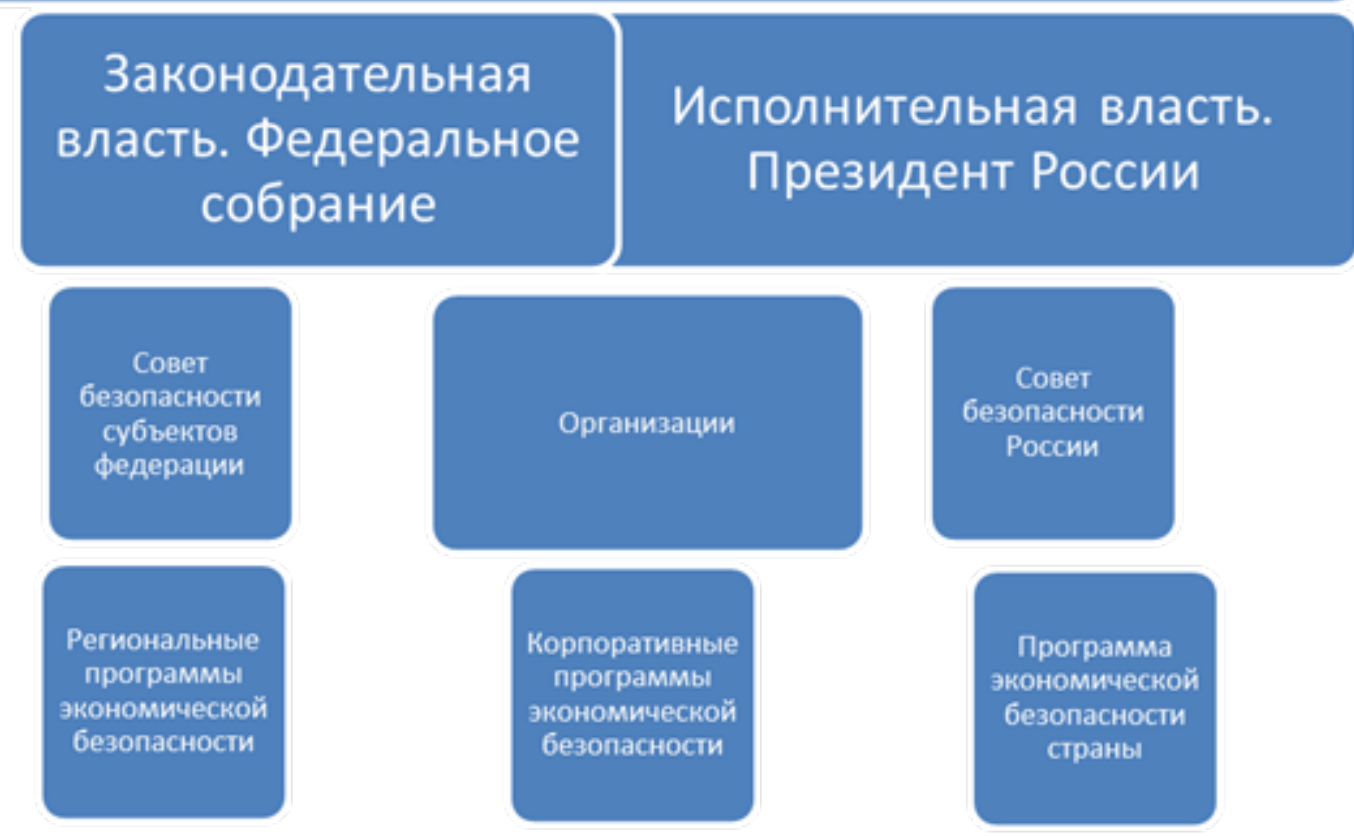

Рисунок 3. Система управления экономической безопасностью [9, с. 90]

Таким образом, экономическая безопасность представляется не как изменчивое состояние, а как мгновенно зафиксированный процесс взаимодействия субъектов, где органу, осуществляющему мониторинг, можно понять логику происходящего без дополнительного изучения причин, вызвавших системные трансформации в хозяйственном комплексе. Целью государственной стратегии экономической безопасности является обеспечение защиты населения, не только путем увеличения качества и уровня жизни, эффективного решения внутренних социальных и экономических задач, но и путем влияния на мировые механизмы, учитывая государственные национальные интересы.

Обратимся к рассмотрению политической и экономической основы обеспечения экономической безопасности. Рассматривая экономическую безопасность как геополитическую категорию, ее можно представить как стабильность национальной экономики перед лицом внешних и внутренних 
угроз как гарантию национального суверенитета в контексте расширения системы международных экономических связей и отношений [8, п. 257].

Невозможно представить современную Россию в отрыве от единой мировой системы экономических отношений (несмотря на введенные санкции). Однако именно введение санкций позволило более четко определить угрозы экономической безопасности, которые влекут за собой бездумное включение интеграционных процессов.

Масштабы соотношения объектов экспорта и импорта, несмотря на реализацию политики импортозамещения, остались на одном уровне. Так, если в 2000 году экспорт превысил импорт в два раза, то это соотношение сохранилось и по сей день.

В результате реализации политики санкций европейских стран объем экспорта и импорта сократился в среднем на 20-25\% и стал сопоставимым с периодом 2009 года. Следует отметить, что в 2017 году отрицательная динамика Внешняя торговля России оставалась с основными торговыми партнерами из стран ЕС в 37285 млрд.долларов, причем страны АТЭС на 9089 млрд. Долларов и страны ЕврАзЭС - на 3585 млрд.долларов. В то же время внешняя торговля росла с такими странами, как Франция, - на 11966 млрд долларов и составила 115,2\% по сравнению с предыдущим годом, Китай - на 58745 млрд долларов (101,7\%), Швейцария - 4,373 трлн долларов США $(107,1 \%)$, и Армении - 1,195 триллиона долларов США (107,3\%) [6, с. 761-771].

Анализ структуры экспорта показывает, что львиная доля минеральных продуктов сохраняется. Если в 2010 году доля их экспорта составила 68,5\%, то к 2017 году она снизилась до 63,8\%.

Аналогичная ситуация характерна для структуры импорта. В импорте наибольшую часть занимают машины, оборудование и транспортные средства, а если в 2010 году их доля составляла 44,4\%, то к 2017 году она увеличилась до $44,8[6]$.

Итак, анализ представленных данных показал, что значительных изменений в рамках реализации политики импортозамещения не произошло, и наша страна сохранила сырьевую ориентацию во внешнеэкономической деятельности. 
Таким образом, нынешняя структура внешней торговли не только не увеличивает угрозу экономической безопасности и способствует развитию национальной экономики в сторону увеличения экономической мощи и продовольственного суверенитета с целью улучшения качества жизни населения, но в некоторых случаях это усугубляет их.

Современная российская система национальных интересов имеет решающее значение для разработки стратегии развития национальной экономики и определения спектра ее возможных траекторий.

Функционирование системы экономической безопасности страны и ее системы поддержки на национальном и региональном уровнях основано на устранении угроз с помощью конкретных мер и механизмов, которые оцениваются по качественным показателям и количественным показателям макроэкономическим, демографическим, внешнеэкономическим, экологическим и т.Д,

Под экономической безопасностью государства понимается состояние экономики, в котором гарантированная защита национальных интересов обеспечивается даже при неблагоприятном воздействии внешних и внутренних факторов.

Система обеспечения экономической безопасности государства является многоуровневой, одна из которых является индикативной системой. Компонентами индикативной системы являются показатели , характеризующие уровень и степень достижения целей социально-экономического развития. В настоящее время вопросам формирования системы показателей экономической безопасности уделяется большое внимание, как со стороны государства, так и со стороны научного сообщества. Указом Президента Российской Федерации от 13 мая 2017 года № 208 утверждена «Стратегия экономической безопасности Российской Федерации на период до 2030 года», рассчитанная на ближайшие годы. Меры по реализации Государственной стратегии экономической безопасности Российской Федерации, утвержденные Указом Президента Российской Федерации от 29 апреля 1996 г. № 608, были направлены на обеспечение осуществления экономических реформ, запланированных на 
следующие три-пять лет, но определил деятельность государства в области экономической безопасности российского государства последние два десятилетия. Стратегия-2017 по сравнению с Стратегией-1996 является стратегическим документом, который включает в себя больше областей государственной деятельности для обеспечения собственной экономической безопасности [7].

Таким образом, в настоящее время перед Россией стоит сложная задача обеспечить реализацию экономического блока национально-государственных интересов через призму решения социальных проблем. Эта проблема, с одной стороны, представляется вполне прозрачной, поскольку она предполагает создание условий для качественного экономического роста, укрепление глобального экономического влияния (как инструмента внешнеэкономической политики), основанного на поддержке и защите внутренних предпринимательства, развития аграрного сектора экономики и перерабатывающей промышленности, развития реальных секторов экономики с уделением особого внимания продуктам с высокой добавленной стоимостью. 


\section{СПИСОК ИСПОЛЬЗОВАННЫХ ИСТОЧНИКОВ}

1. Закон РФ от 28.12.2010 № 390-Ф3 (ред. от 05.10.2015) «О безопасности» (с изм. и доп.) // Российская газета № 295 от 29.12.2010 // Парламентская газета № 1-2 от 14.01.2011 // СЗ РФ № 1 ст.2 от 03.01.2011

2. Берднева Л.Б. Измерение дифференциации регионов по уровню валового регионального продукта на душу населения // Проблемы современной науки. 2014. № 15. С. 99-102.

3. Володин В.М. Механизмы обеспечения экономической безопасности // Модели, системы, сети в экономике, технике, природе и обществе. 2016. № 1. С. 49, C. $48-52$.

4. Карпенко Т.Г. Деятельность таможенных органов в обеспечении экономической безопасности: монография. - Ульяновск: изд-во «Зебра», 2016. C. 57.

5. Овсянникова Е.В. Экономическая безопасность в системе национальной безопасности Российской Федерации в условиях глобализации: монография. - М.: МИТ, 2014. С. 59.

6. Радюкова Я.Ю. Согласование экономических интересов в системе обеспечения экономической безопасности страны / Радюкова Я.Ю., Якунина И.Н., Колесниченко Е.А. // Российское предпринимательство. - 2017. - Том 18. № 5. - С. 761-771.

7. Попов А.И. Хозяйственная система России: инновационное развитие и экономическая безопасность: Учебное пособие / Попов А.И., Иванов С.А., Миэринь Л.А.. - СПб: Издательство СПбГУЭФ, 2009. - 338 с.

8. Радюкова Я.Ю., Сутягин В.Ю. Экономические санкции: вызовы и возможности для российского сельского хозяйства // Труды Вольного экономического общества России. - 2016. - Т. 202. - С. 257-276.

9. Юдин О. Инновационные преобразования как императив устойчивого развития и экономической безопасности России. - М.: АНКИЛ, 2013. С. 90.

10. Шумилина В. Е., Широкобородова А. А., Никитина Е. А. Анализ внешних и внутренних угроз экономической безопасности Российской Федерации // Актуальные вопросы обеспечения экономической безопасности в 
Российской Федерации в условиях цифровой экономики . AUS PUBLISHERS . 2018. C. 1-8. URL: https: //auspublishers.com.au/ru/nauka/ conference_article/2132/view (дата обращения: 18.11.2018).

\section{References:}

1. Law of the Russian Federation of 12/28/2010 No. 390-FZ (as amended on 10/05/2015) “On Security” (as amended and added) // Rossiyskaya gazeta No. 295 of 12/29/2010 // Parliamentary Newspaper No. 1-2 dated January 14, 2011 // SZ RF No. 1, Article 2 dated January 3, 2011

2. Berdneva L.B. Measurement of differentiation of regions by the level of gross regional product per capita // Problems of modern science. 2014. No. 15. S. 99102.

3. Volodin V.M. Mechanisms to ensure economic security // Models, systems, networks in the economy, technology, nature and society. 2016. No. 1. S. 49, S. 4852.

4. Karpenko T.G. The activities of customs authorities in ensuring economic security: a monograph. - Ulyanovsk: publishing house "Zebra", 2016, p. 57.

5. Ovsyannikova E.V. Economic security in the system of national security of the Russian Federation in the context of globalization: a monograph. - M $\therefore$ MIT, 2014. P. 59.

6. Radyukova Y. Yu. Coordination of economic interests in the system of ensuring the economic security of the country / Radyukova J.Yu., Yakunina I.N., Kolesnichenko E.A. // Russian entrepreneurship. - 2017. - Vol. 18. - No. 5. - P. 761771.

7. Popov A.I. Economic System of Russia: Innovative Development and Economic Security: Study Guide / Popov, AI, Ivanov, SA, Myerin, L.A .. - SPb: Publishing House of St. Petersburg State University of Economics and Finance, 2009. -338 p.

8. Radyukova Y. Yu., Sutyagin V. Yu. Economic sanctions: challenges and opportunities for Russian agriculture // Proceedings of the Free Economic Society of Russia. - 2016. - T. 202. - C. 257-276.

9. Yudin O. Innovative transformations as an imperative of sustainable development and economic security of Russia. - M .: ANKIL, 2013. P. 90. 
10. Shumilina V. E., Shirokoborodova A. A., Nikitina E. A. The analysis of external and internal threats of economic security of the Russian Federation//Topical issues of ensuring economic security in the Russian Federation in the conditions of digital economy. AUS PUBLISHERS. 2018. Page 1-8. URL: https://auspublishers.com.au/ru/nauka/conference_article/2132/view (date of the address: 18.11.2018). 